\title{
Altura de pastejo de aveia e azevém e qualidade física de um Latossolo Vermelho distroférrico sob integração lavoura-pecuária
}

\section{Height of grazing of oats and rye grass crops and physical quality of an Oxisol under farming-livestock integration}

\author{
Leonardo Pim Petean ${ }^{1 *}$; Cássio Antonio Tormena ${ }^{1}$; \\ Jonez Fidalski²; Sérgio José Alves ${ }^{3}$
}

\begin{abstract}
Resumo
A intensidade do pisoteio dos animais durante o pastejo das forrageiras pode comprometer a qualidade física do solo no sistema de integração lavoura-pecuária. O objetivo deste trabalho foi avaliar a influência da altura de pastejo de aveia e azevém na qualidade física do solo sob integração lavoura-pecuária. $\mathrm{O}$ experimento foi implantado em 2002, no município de Campo Mourão (PR), em um Latossolo Vermelho distroférrico textura muito argilosa, com a semeadura direta de soja no verão e de aveia e azevém no inverno. Foram avaliados os tratamentos de alturas de pastejo de aveia e azevém mantidos a 7, 14, 21 e $28 \mathrm{~cm}$, comparados a um tratamento testemunha sem pastejo de aveia e azevém. Em novembro de 2005, foram coletadas amostras indeformadas de solo nas camadas de 0-7,5 e 7,5-15cm de profundidade. Determinaram-se 10 indicadores de qualidade física do solo. Para manter a qualidade física de um Latossolo Vermelho distroférrico textura muito argilosa, na profundidade de $0-15 \mathrm{~cm}$, sob pastejo da aveia e azevém no inverno, a altura de pastejo deve ser mantida a $21 \mathrm{~cm}$

Palavras-chave: Densidade do solo, compactação do solo, porosidade total
\end{abstract}

\begin{abstract}
The intensity of animal trampling during forage-plant grazing can promote deleterious modifications in the physical quality of soils in farming-livestock integrated systems. The objective of this study was to evaluate the influence of height of grazing of oats and rye grass crops on the physical quality of the soil under farming-livestock integrated systems. The experiment was carried in 2002 in the county of Campo Mourão, Paraná State, Brazil in an Oxisol (Typic Paleudult), with very clayey texture, with the direct sowing of soy bean in the summer and of oats and rye grass crops in the winter. The treatments of grazing of oats and rye grass crops were maintained to $7,14,21$ and $28 \mathrm{~cm}$, compared to a control treatment without grazing. In November of 2005, undisturbed soil samples were collected in the layers of $0-7.5$ and $7.5-15 \mathrm{~cm}$ of depth. Ten indicators of physical quality of the soil were evaluated. To maintain the physical quality of a very clayey Oxisol, in the depth of $0-15 \mathrm{~cm}$, under grazing of oats and rye grass crops in the winter, the grazing height should be maintained to $21 \mathrm{~cm}$.
\end{abstract}

Key words: Soil bulk density, soil compaction, total porosity

1 Universidade Estadual de Maringá (UEM). Departamento de Agronomia; Maringá, PR. E-mail: leonardopim@hotmail.com

Instituto Agronômico do Paraná (IAPAR). Paranavaí, PR.

3 Instituto Agronômico do Paraná (IAPAR). Londrina, PR.

Autor para correspondência 


\section{Introdução}

A integração lavoura-pecuária pode ser definida como a alternância temporária ou a rotação, numa mesma área, de culturas de grãos e pastagens destinadas à produção animal (MORAES et al., 1998). Na região Sul do Brasil, as pastagens anuais de inverno são formadas principalmente por aveia e azevém, após o cultivo de soja ou milho no verão, semeadas em sistema convencional e plantio direto, e são boas alternativas para a produção de grãos, forragem e carne (SILVA; REINERT; REICHERT, 2000; LANZANOVA et al., 2007; LOPES et al., 2008).

A presença de animais na pastagem tem efeitos sobre a produção de forragem e a qualidade física do solo (SILVA; REINERT; REICHERT, 2000; LANZANOVA et al., 2007). Os cascos dos animais causaminjúrias à vegetação e compactaçãona camada superficial do solo (BALPH; MALECHECK, 1985; LANZANOVA et al., 2007).

Maior produção por área e ganho médio diário de novilhos precoces sob manejo de aveia e azevém, a $10 \mathrm{~cm}$ e $25-30 \mathrm{~cm}$ de altura, foram obtido por Lopes et al. (2008) em sistema de integração lavourapecuária de soja no verão e aveia e azevém no inverno, quando comparados com uma altura de 40 $\mathrm{cm}$, no manejo do pasto. A intensidade de pisoteio é determinante na compactação do solo sob integração lavoura-pecuária com aveia e azevém no inverno no sul do Brasil, conforme relatam (SILVA; REINERT; REICHERT, 2000; LANZANOVA et al., 2007), que avaliaram as alterações da qualidade física do solo por meio do ajuste da carga animal sobre pastejo contínuo ou pela freqüência de pastejo rotacionado.

$\mathrm{Na}$ quantificação da qualidade física do solo algumas propriedades físicas tem sido utilizadas, como a densidade e a porosidade do solo. Outros indicadores de qualidade física do solo tais como a porosidadenodomíniodos macroporos ea porosidade da matriz do solo, respectivamente, equivalentes aos diâmetros de poros superiores e inferiores a 300 $\mu \mathrm{m}$ também têm sido utilizados (REYNOLDS et al., 2002). O desdobramento destas duas classes de poros é justificado pelas funções de armazenamento e transmissão de água e ar. Reynolds et al. (2002) também sugeriram como indicadores a capacidade de aeração total do solo e a a capacidade de aeração da matriz do solo, estimados respectivamente pela diferença dos teores de água do solo saturado e na tensão de $10 \mathrm{kPa}$ e do teor de água na tensão de $1 \mathrm{kPa}$ menos o teor de água na tensão de $10 \mathrm{kPa}$. $\mathrm{O}$ teor de água no solo equivalente à tensão de 10 $\mathrm{kPa}$ corresponde àquele na capacidade de campo, considerado o limite superior de água disponível no solo (TORMENA et al., 2007).

O objetivo deste trabalho foi avaliar a altura de pastejo de azevém e aveia que não comprometesse a qualidade física do solo sob integração lavourapecuária.

\section{Material e métodos}

Otrabalho foiconduzidonaFazendaExperimental da COAMO - Cooperativa Agroindustrial, localizada no município de Campo Mourão, Estado do Paraná, $\left(24^{\circ} 02^{\prime}\right.$ S e $52^{\circ} 22^{\prime}$ W). O tipo climático dominante segundo a classificação de Köppen é o Cfa (subtropical úmido mesotérmico). O solo utilizado é classificado como Latossolo Vermelho distroférrico com teores médios de $850 \mathrm{~g} \mathrm{~kg}^{-1}$ de argila, $120 \mathrm{~g} \mathrm{~kg}^{-1}$ de silte e $30 \mathrm{~g} \mathrm{~kg}^{-1}$ de areia, classe textural muito argilosa (EMPRESA BRASILEIRA DE PESQUISA AGROPECUÁRIA, 2006).

O experimento foi implantado em 2002 em uma área de 8 ha, consistindo do sistema de integração lavoura-pecuária com a semeadura direta de soja no verão e aveia e azevém no inverno. Foram avaliados os tratamentos de alturas de pastejo de aveia e azevém mantidos a 7, 14, 21 e $28 \mathrm{~cm}$, e um tratamento testemunha sem pastejo de aveia e azevém. Foram utilizadas duas repetições por tratamento, dispostas uma ao lado da outra. A testemunha foi mantida no interior de cada repetição em que se delimitou uma área de cerca de $100 \mathrm{~m}^{2}$, à qual os animais não tiveram acesso durante o período experimental. 
Após o cultivo de soja, a aveia e azevém foram semeadas e os tratamentos foram delimitados com cerca elétrica, com áreas de diferentes tamanhos em função da altura de pastejo a ser mantida na forrageira. Anualmente, a altura de pastejo da pastagem foi monitorada semanalmente durante o período de 120 dias e ajustada com taxas de lotações médias de 2,44; 2,61; 2,25 e 1,82UA ha-1, respectivamente, para os tratamentos de 7, 14, 21 e $28 \mathrm{~cm}$ de altura. Foi utilizado o método de pastejo contínuo com a técnica de "put and take". Em cada unidade experimental permaneciam dois animais "testers" e um número variável de animais reguladores, utilizados de forma a se manter os diferentes tratamentos de altura da pastagem.

Quinzenalmente, com o auxílio do aparelho denominado "sward stick", em 20 pontos amostrais por parcela, foi feito o ajuste da carga animal, permanecendo com a entrada ou retirada dos animais reguladores.

Em novembro de 2005, após a retirada dos animais sob pastejo de aveia e azevém, foram coletadas 36 amostras indeformadas de solo em cada tratamento em cada uma das camadas (0-7,5 e 7,5$15 \mathrm{~cm}$ de profundidade), utilizando-se de cilindros de aço com $5 \mathrm{~cm}$ de comprimento e diâmetro.

No laboratório as amostras foram saturadas com uma solução de $\mathrm{CaCl}_{2} 0,01 \mathrm{~mol} \mathrm{~L}^{-1}$, por $24-48 \mathrm{~h}$. As amostras foram pesadas em condição de saturação e submetidas nas tensões de 1 e $6 \mathrm{kPa}$, em mesa de tensão e a $10 \mathrm{kPa}$ utilizando placas porosas e extratores de Richards (EMBRAPA, 1997). Ao cessar a drenagem de água, as amostras foram novamente pesadas antes e após serem levadas para estufa a $\pm 105^{\circ} \mathrm{C}$ por $24 \mathrm{~h}$. A partir da massa de sólidos do solo e do volume total, calculado para cada amostra, obteve-se a densidade do solo. A densidade de partículas foi determinada pelo método do balão volumétrico conforme EMBRAPA (1997), utilizando um valor de $2,85 \mathrm{Mg} \mathrm{m}^{-3}$ (obtido de 33 amostras coletadas aleatoriamente na área experimental), para estimar a porosidade total. O teor de água do solo após equilíbrio na tensão de 6 $\mathrm{kPa}$, foi considerado equivalente à microporosidade do solo e a macroporosidade foi calculada pela diferença entre a porosidade total e o teor de água na tensãp de $6 \mathrm{kPa}$ (EMBRAPA, 1997).

Outros indicadores de qualidade física foram obtidos conforme Reynolds et al. (2002): a) porosidade no domínio dos macroporos do solo (teor de água do solo saturado subtraído do teor de água na tensão de $\left.1 \mathrm{kPa}, \mathrm{m}^{3} \mathrm{~m}^{-3}\right)$; b) porosidade no domínio da matriz do solo (teor de água na tensão de $1 \mathrm{kPa}$, $\mathrm{m}^{3} \mathrm{~m}^{-3}$ ); c) capacidade de ar do solo (teor de água na saturação subtraído do teor de água na tensão de $\left.10 \mathrm{kPa}, \mathrm{m}^{3} \mathrm{~m}^{-3}\right)$; ) capacidade de ar da matriz do solo (teor de água na tensão de $1 \mathrm{kPa}$ subtraído do teor de água na tensão de $\left.10 \mathrm{kPa}, \mathrm{m}^{3} \mathrm{~m}^{-3}\right)$; e) capacidade de armazenamento de água (razão entre capacidade de campo e porosidade total; (adimensional); f) e a capacidade de armazenamento de ar (razão entre capacidade do ar do solo e porosidade total do solo (adimensional). O teor de água equivalente a capacidade de campo foi considerado aquele na tensão de $10 \mathrm{kPa}$.

O intervalo de confiança da média 95\% $(\mathrm{P}<0,05)$ foi utilizado como critério estatístico para discriminação dos efeitos dos tratamentos nos indicadores de qualidade física do solo. Quando não houve sobreposição dos limites superior e inferior do intervalo de confiança considerou-se que houve diferenças significativas entre os tratamentos conforme Payton, Miller e Raun (2000).

\section{Resultados e discussão}

Os indicadores de qualidade física do solo densidade do solo, macroporosidade, microporosidade, porosidade total e porosidade no domínio dos macroporos do solo caracterizaram que o tratamento de $28 \mathrm{~cm}$ de pastejo foi semelhante ao tratamento testemunha, e que os tratamentos 7 , 14 e $21 \mathrm{~cm}$ de altura de pastejo comprometeram a qualidade física do solo na camada de $0-7,5 \mathrm{~cm}$ de profundidade (Figuras 1 e 2). Estes indicadores 
de qualidade física do solo não identificaram resultados são semelhantes aos de Bertol et al. diferenças entre os tratamentos na camada de 7,5- (2000), Greenwood, Mcleod e Hutchinson (1997) e $15 \mathrm{~cm}$ de profundidade, sugerindo que os efeitos Lanzanova et al. (2007), o que indica que os efeitos do manejo, especificamente do pisoteio animal, da compactação pelo pisoteio animal concentram-se ficaram localizados na camada superficial. Tais na camada superficial do solo.
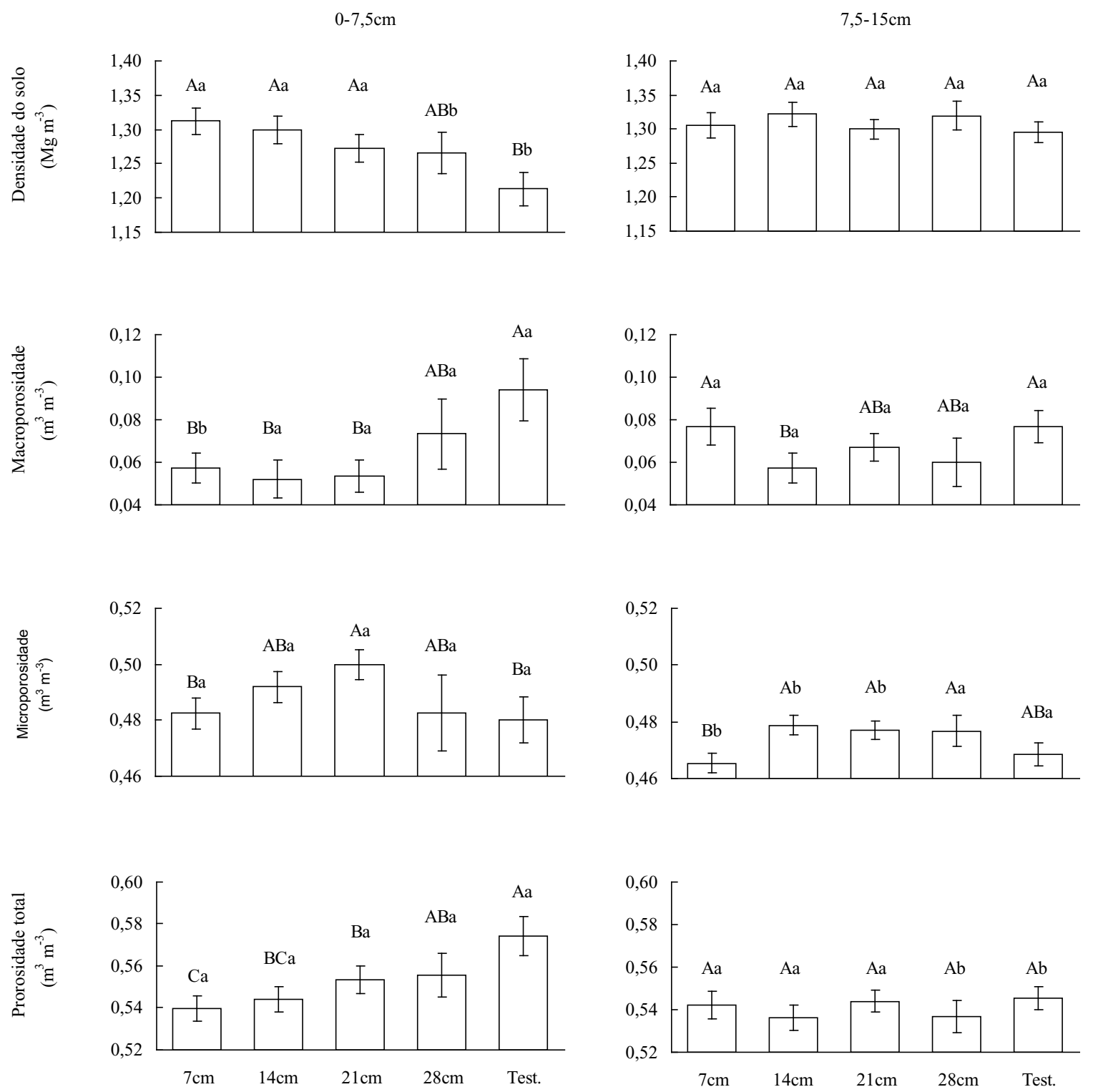

Figura 1. Valores médios e intervalos de confiança da média para a densidade do solo, maroporosidade, microporosidade e porosidade total, nas camadas de $0-7,5 \mathrm{~cm}$ e $7,5-15 \mathrm{~cm}$ de profundidade, para os tratamentos de altura de pastejo $(7,14,21$ e $28 \mathrm{~cm})$ comparados com o tratamento testemunha sem pastejo (Test.). Letras maiúsculas iguais indicam sobreposição dos intervalos de confiança da média $(\mathrm{P}<0,05)$ entre os tratamentos dentro da mesma camada de solo, e letras minúsculas iguais não diferem os intervalos de confiança da média do mesmo tratamento entre as duas camadas de solo. 
$0-7,5 \mathrm{~cm}$

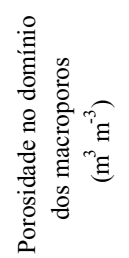

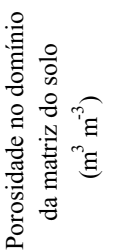

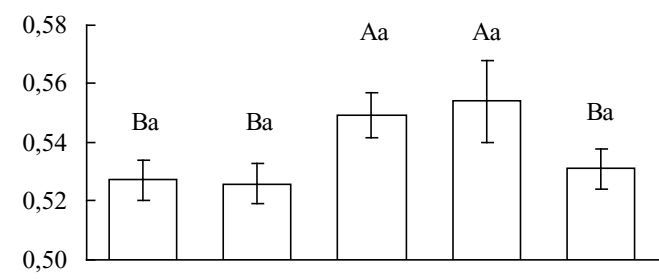

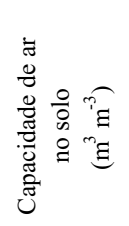
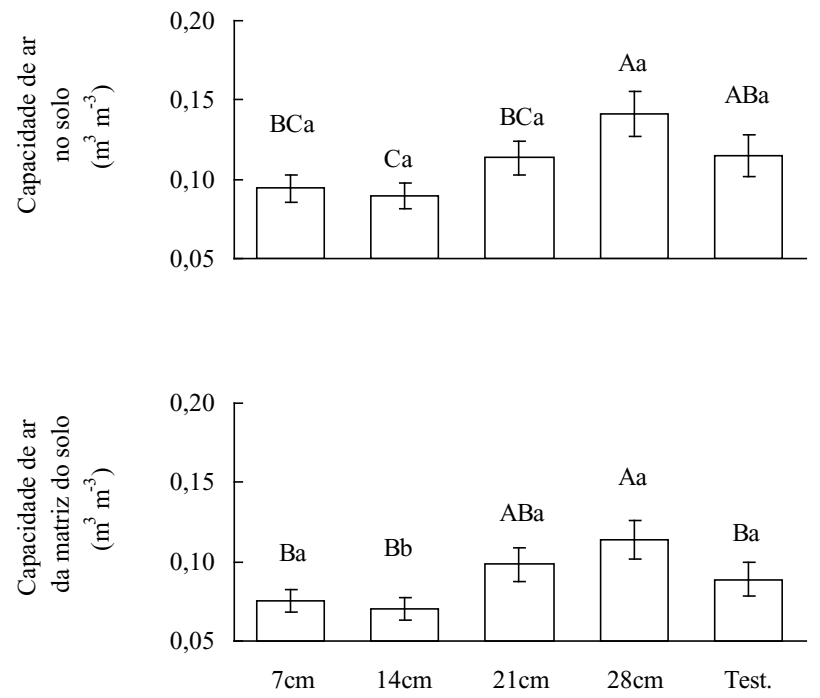

$7,5-15 \mathrm{~cm}$
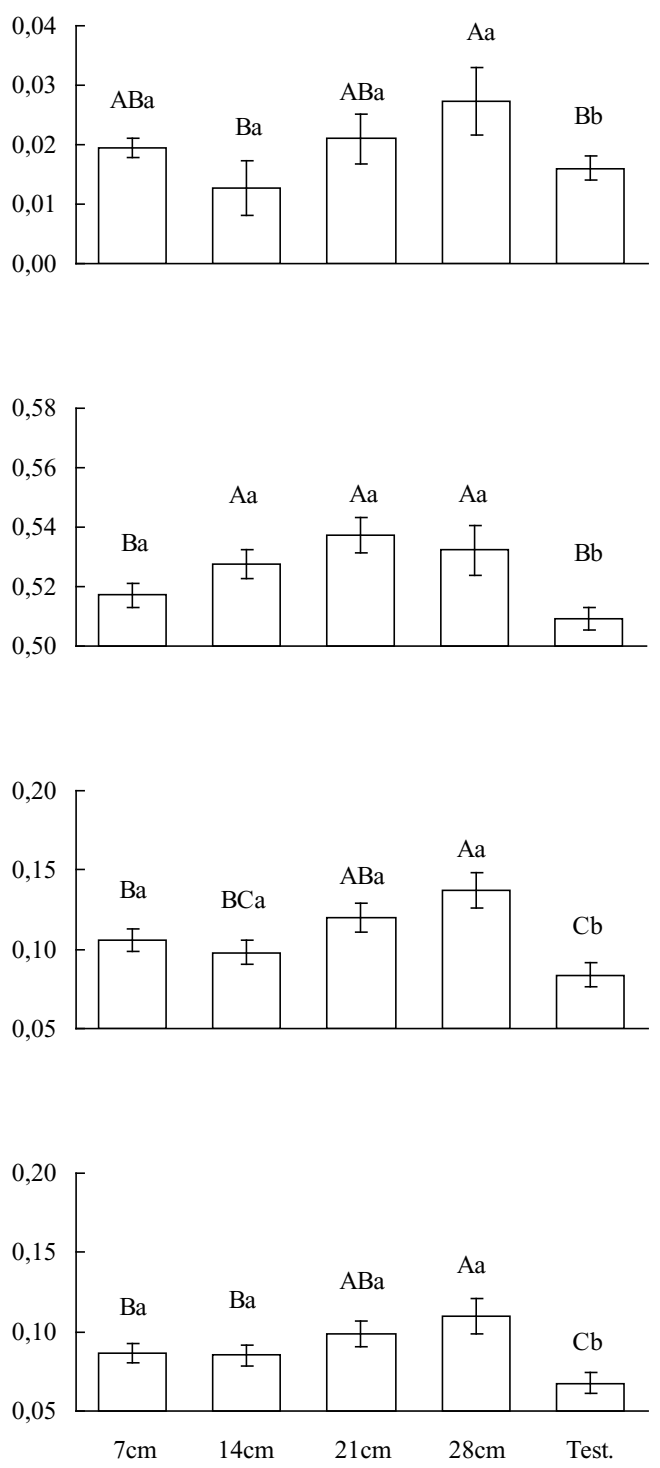

Figura 2. Valores médios e intervalos de confiança da média para a porosidade no domínio dos macroporos do solo, porosidade no domínio da matriz do solo , capacidade de ar do solo ) e capacidade de ar da matriz do solo, nas camadas de $0-7,5 \mathrm{~cm}$ e $7,5-15 \mathrm{~cm}$ de profundidade, para os tratamentos de altura de pastejo $(7,14,21$ e $28 \mathrm{~cm})$ comparados com a testemunha sem pastejo (Test.). Letras maiúsculas iguais não diferem os intervalos de confiança da média $(\mathrm{P}<0,05)$ entre os tratamentos dentro da mesma camada de solo, e letras minúsculas iguais não diferem os intervalos de confiança da média do mesmo tratamento entre as duas camadas de solo.

O manejo da altura de pastejo de $21 \mathrm{~cm}$ distinguiu melhor a macroporosidade, microporosidade e porosidade total em relação ao tratamento testemunha (Figura 1). Os resultados indicam que a redução da porosidade total ocorreu via redução da macroporosidade em solo de textura argilosa. O aumento da densidade do solo com a compactação em outros sistemas de manejo foi também relatada por Albuquerque et al. (1995).

O pisoteio animal nos tratamentos 7, 14 e $21 \mathrm{~cm}$ reduziu a porosidade no domínio dos macroporos 
na camada de 0-7,5 cm (Figura 2), comparado aos tratamentos testemunha e $28 \mathrm{~cm}$ de altura de pastejo em acordo com Reynolds et al. (2002), o que pode comprometer a infiltração de água no solo em tensões próximas a saturação (LANZANOVA et al., 2007). Em relação a este indicador, a camada de $7,5-15 \mathrm{~cm}$ teve valores semelhantes à camada de $0-7,5 \mathrm{~cm}$, porém no tratamento testemunha verificou-se redução em seus valores, devido à maior concentração das raízes de aveia na camada superficial e à reduzida população de plantas de azevém nesse tratamento.

A porosidade no domínio dos macroporos do solo foi igual e superior ao tratamento testemunha nas camadas de $0-7,5$ e 7,5-15cm (Figura 2). Isto significa que estes tratamentos apresentaram maior porosidade em alta tensão $(1 \mathrm{kPa})$, de acordo com Reynolds et al. (2002). Tais resultados são importantes para solos muito argilosos.

A altura de pastejo teve um efeito positivo ao incrementar a porosidade no domínio da matriz do solo nos tratamentos 21 e $28 \mathrm{~cm}$ nas camadas de 0-7,5 e 7,5-15cm, caracterizando poros de menores diâmetros quando comparados à testemunha (Figura 1 e 2). Reynolds et al. (2002) também verificaram diferenças entre sistemas de uso e manejo do solo, demonstrando que solos cujos manejos estabeleciam melhores condições físicas solo implicavam num aumento dos valores deste indicador de qualidade física.

Os maiores valores médios da porosidade no domínio da matriz do solo, capacidade de ar do solo, capacidade de ar da matriz do solo e capacidade de armazenamento de ar na camada de $0-7,5$ e $7,5-15 \mathrm{~cm}$ para os tratamentos 21 e $28 \mathrm{~cm}$ em relação a testemunha (Figuras 2 e 3), indicam melhor continuidade dos poros, o que garante maior facilidade para as troca de gases no solo, como preconizado por Reynolds et al. (2002). De acordo com Lanzanova et al. (2007), a freqüência de pastejo de aveia e azevém compromete a macroporosidade do solo na camada de $10-15 \mathrm{~cm}$.
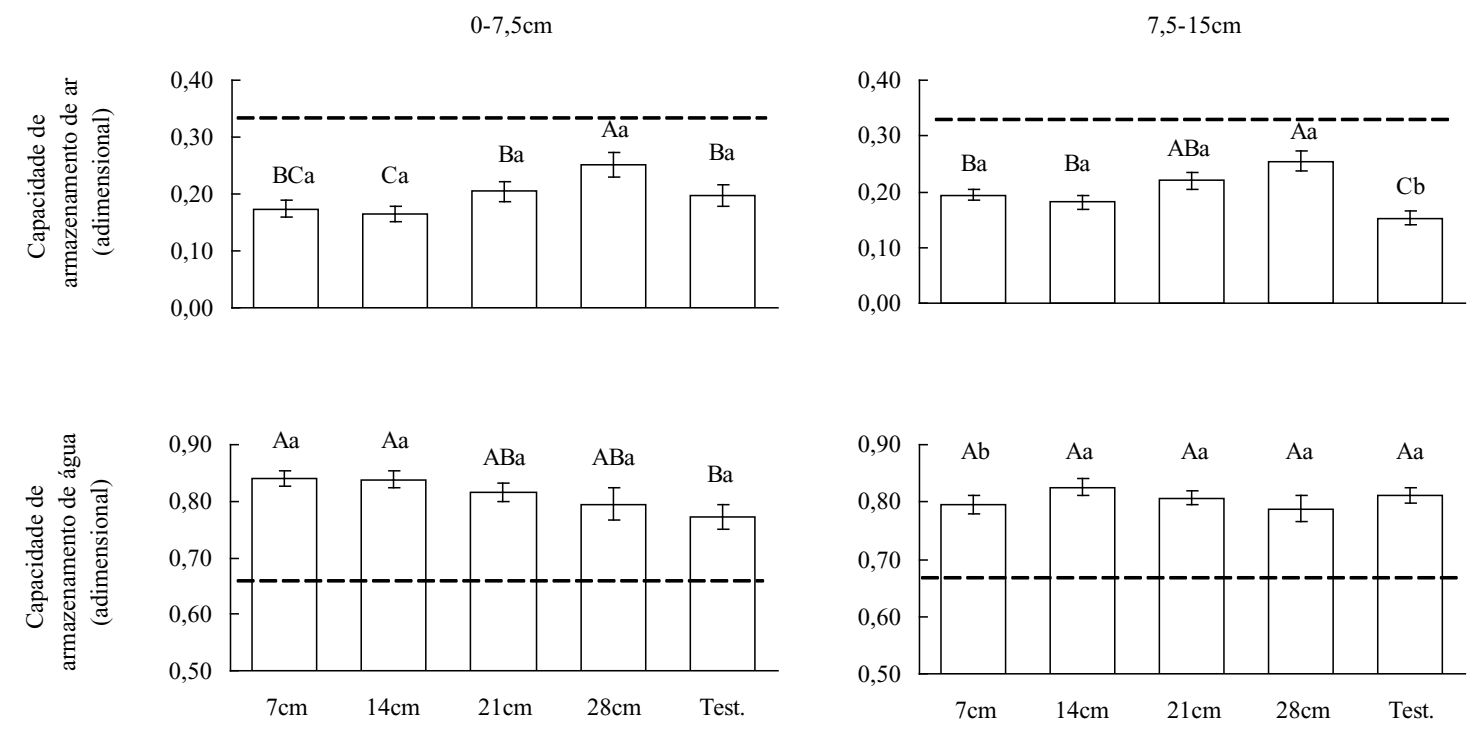

Figura 3. Valores médios e intervalos de confiança da média para a capacidade de armazenamento de ar (adimensional) e capacidade de armazenamento de água (adimensional), nas camadas de $0-7,5 \mathrm{~cm}$ e $7,5-15 \mathrm{~cm}$ de profundidade, para os tratamentos de altura de pastejo $(7,14,21 \mathrm{e} 28 \mathrm{~cm})$ comparados com a testemunha sem pastejo (Test.). Letras maiúsculas iguais não diferem os intervalos de confiança da média $(\mathrm{P}<0,05)$ entre os tratamentos dentro da mesma camada de solo, e letras minúsculas iguais não diferem os intervalos de confiança da média do mesmo tratamento entre as duas camadas de solo.As linhas horizontais referem-se aos limites proposto por Olness et al. (1998) (apud REYNOLDS et al., 2002). 
Considerando a capacidade de ar em torno de $0,10 \mathrm{~m}^{3} \mathrm{~m}^{-3}$ como sendo o volume mínimo adequado do solo para a aeração das raízes (TOPP et al., 1997), apenas os tratamentos 21 e $28 \mathrm{~cm}$ nas camadas de 0-7,5 e 7,5-15cm atenderam este índice mínimo. A diferença de tensão desses indicadores de qualidade física do solo com a macroporosidade é de 4 e $5 \mathrm{kPa}$, respectivamente para capacidade de ar da matriz do solo e capacidade de ar no solo (Figuras 1 e 2). Se fosse utilizada a macroporosidade com referência no valor estabelecido por Topp et al. (1997), nenhum tratamento em nenhuma das duas profundidades atenderia o índice mínimo de $0,10 \mathrm{~m}^{3} \mathrm{~m}^{-3}$. Isto significa que os indicadores de capacidade de ar da matriz e no solo estão mais coerentes com a menor densidade do solo, verificada na camada de $0-7,5 \mathrm{~cm}$ do tratamento de $28 \mathrm{~cm}$ de altura de pastejo.

O tratamento de $21 \mathrm{~cm}$ de altura de pastejo, na camada de $0-7,5 \mathrm{~cm}$, foi estatisticamente igual ao tratamento testemunha para os indicadores de capacidade de armazenamento de água e para a capacidade de armazenamento de ar (Figura 3). Os valores destes indicadores aproximam-se dos valores ideais estabelecidos por Reynolds et al. (2002), como balanço ideal entre a capacidade de reter água e manter a aeração do solo, de 0,66 (adimensional) para a capacidade de armazenamento de água e 0,34 (adimensional) para a capacidade de armazenamento de ar.

Os resultados deste trabalho mostraram que para manter a qualidade física de um Latossolo Vermelho distroférrico textura muito argilosa sob o sistema de integração lavoura-pecuária há necessidade de manter a altura de pastejo mínima de $21 \mathrm{~cm}$ para os diferentes indicadores de qualidade física do solo (Figuras 1, 2 e 3). Esses resultados corroboram com o estudo de Lopes et al. (2008), os quais estabeleceram maior ganho de peso médio diário de novilhos precoces quando utilizaram este sistema de integração lavoura-pecuária com o manejo de aveia e azevém a $25-30 \mathrm{~cm}$ de altura, em solo similar ao do presente trabalho.

\section{Conclusões}

Para manter a qualidade física de um Latossolo Vermelho distroférrico textura muito argilosa, na profundidade de $0-15 \mathrm{~cm}$, sob pastejo da aveia e azevém no inverno, a altura de pastejo deve ser mantida, no mínimo, a $21 \mathrm{~cm}$.

\section{Referências}

ALBUQUERQUE, J. A.; REINERT, D. J.; FIORIN, J. E.; RUEDELL, J.; PETRERE, C.; FORTINELLI, F. Rotação de culturas e sistemas de manejo do solo: efeito sobre a forma da estrutura do solo ao final de sete anos. Revista Brasileira de Ciência do Solo, Campinas, v. 19, n. 1, p. 115-119, 1995.

BALPH, D. F.; MALECHECK, J. C. Cattle trampling of crested wheat-grass under short-duration grazing. The Journal of Range Management Archives, Arizona, v. 38, n. 3, p. 226-227, 1985.

Bertol, I.; AlmeidA, J. A.; ALMEIDA, E. X.; KURTZ, C. Propriedades físicas do solo relacionado a diferentes níveis de oferta de forragem de capim elefanteanão cv Motti. Pesquisa Agropecuária Brasileira, Brasília ,v. 35, n. 5, p. 1047-1054, 2000.

EMPRESA BRASILEIRA DE PESQUISA AGROPECUÁRIA - EMBRAPA. Manual de métodos de análise de solo. 2. ed. Rio de Janeiro: Centro Nacional de Pesquisa de Solos, 1997. 212 p. (Embrapa-CNPS. Documentos, n.1).

EMPRESA BRASILEIRA DE PESQUISA AGROPECUÁRIA - EMBRAPA. Sistema brasileiro de classificação de solos. Rio de Janeiro: Embrapa Solos, 2006.

GREENWOOD,K.L.;MCLEOD,D.A.;HUTCHINSON, K. J. Long-term stocking rate effects on soil physical properties. Australian Journal of Experimental Agriculture, Collingwood, v. 37, n. 4, p. 413-419, 1997.

LANZANOVA, M. E.; NICOLOSO, R. S.; LOVATO, T.; ELTZ, F. L. F.; AMADO, T. J. C.; REINERT, D. J. Atributos físicos do solo em sistema de integração lavoura-pecuária sob plantio direto. Revista Brasileira de Ciência do Solo, Viçosa, v. 31, n. 5, p. 1131-1140, 2007.

LOPES, M. L. T.; CARVALHO, P. C. F.; ANGHINONI, I.; SANTOS, D. T.; KUSS, F.; FREITAS, F. K.; FLORES, J. P. C. Sistema de integração lavoura-pecuária: desempenho e qualidade da carcaça de novilhos superprecoces 
terminados em pastagem de aveia e azevém manejada sob diferentes alturas. Ciência Rural, Santa Maria, v. 38, n. 1, p. 178-184, 2008.

MORAES, A.; PELISSARI, A.; ALVES, S. J.; CARVALHO, P. C. F.; CASSOL, L. C. Lavoura-pecuária em sistemas integrados na pequena propriedade. In: ENCONTRO LATINO AMERICANO SOBRE PLANTIO DIRETO NA PEQUENA PROPRIEDADE, 3., 1998, Pato Branco. Anais... Pato Branco: CEFET-PR, 1998. CD-ROM.

OLNESS, A.; CLAPP, C.E.; LIU, R.; PALAZZO, A.J. Biosolids and their effects on soil properties. In: WALLACE, A.; TERRY, R.E. (Eds.), Handbook of Soil Conditioners. Marcel Dekker, New York, NY, 1998. p.141-165.

PAYTON, M. E; MILLER, A. E.; RAUN, W. R. Testing statistical hypotheses using standard error bars and confidence intervals. Communications in Soil Science and Plant Analysis, Philadelphia, v. 31, n. 5, p. 547-552, 2000.
REYNOLDS, W. D.; BOWMAN, B. T.; DRURY, C. F.; TAN, C. S.; LU, X. Indicators of good soil physical quality: density and storage parameters. Geoderma, Amsterdam, v. 110, n. 1/2, p. 131-146, 2002.

SILVA, V. R.; REINERT, D. J.; REICHERT, J. M. Densidade do solo, atributos químicos e sistema radicular do milho afetados pelo pastejo e manejo do solo. Revista Brasileira de Ciência do Solo, Viçosa, v. 24, n. 1, p. 191199, 2000.

TOPP, G. C.; REYNOLDS, W. D.; COOK, F. J.; KIRBY, J. M.; CARTER, M. R. Physical attributes of soil quality. In: GREGORICH, E. G.; CARTER, M. R. (Ed.). Soil quality for crop production and ecosystem health. Amsterdam: Elsevier Science, 1997. p. 21-58.

TORMENA, C. A.; ARAÚJO, M. A.; FIDALSKI, J.; COSTA, J. M. Variação temporal do interval hidrico otimo deum Latossolo Vermelho distroferrico sob sistema de plantio direto. Revista Brasileira de Ciência do Solo, Viçosa, v. 31, n. 2, p. 211-219, 2007. 